\title{
EDGAR POE EM TRADUÇÃO: MALLARMÉ, ARTAUD, HERBERTO HELDER
}

\author{
Izabela Leal \\ Marcelo Jacques de Moraes
}

O poeta português Herberto Helder, no livro Doze nós numa corda, inteiramente dedicado à tradução, apresenta o poema "Israfel", de Edgar Allan Poe, no original, acompanhado de três traduções, a de Mallarmé, a de Artaud e a sua própria. Esse jogo de traduções aponta, por um lado, para a construção de uma linhagem poética, por outro, ao evidenciar a distância entre o texto de partida e o texto de chegada, como ocorrerá na tradução de Artaud, dá lugar a uma operação transgressora. Pois se a tradução de Mallarmé é praticamente um decalque semântico do original, acompanhando o movimento do poema de Poe quase palavra por palavra, a de Artaud é efetivamente uma releitura do original - uma transluciferação, como diria Haroldo de Campos -, não se prendendo a ele em termos de forma ou mesmo de conteúdo. E a tradução de Herberto Helder, por sua vez, também pode ser considerada transgressora por executar o famoso "interdito" para o qual Benjamin havia apontado em "A tarefa do tradutor": a tradução da tradução. Esse é, no livro em questão, o único caso de um texto que, ao ser traduzido por Herberto Helder, é apresentado no original e em outras versões.

Nossa hipótese de trabalho é a de que, assim como o poema de Poe antecipa em versos o "princípio poético" que ele próprio explicitaria em seus ensaios, as traduções também funcionam como enunciação da poética desses autores, de acordo com um dos preceitos básicos 
de Haroldo de Campos que se aplica muito bem a esse infinito jogo de espelhos: "Na tradução, mais do que em nenhuma outra operação literária, se virtualiza a noção de mimese, não como teoria da cópia ou do reflexo salivar, mas como produção da diferença no mesmo" (CAMPOS, 1981, p. 183).

\section{O POEMA DE POE}

In Heaven a spirit doth dwell

"Whose heart-strings are a lute";

None sing so wildly well

As the angel Israfel,

And the giddy stars (so legends tell),

Ceasing their hymns, attend the spell

Of his voice, all mute.

Tottering above

In her highest noon,

The enamoured moon

Blushes with love,

While, to listen, the red levin

(With the rapid Pleiads, even,

Which were seven,)

Pauses in Heaven.

And they say (the starry choir

And the other listening things)

That Israfel's fire

Is owing to that lyre

By which he sits and sings -

The trembling living wire

Of those unusual strings.

But the skies that angel trod,

Where deep thoughts are a duty,

Where Love's a grown-up God,

Where the Houri glances are

Imbued with all the beauty

Which we worship in a star.

Therefore, thou art not wrong,

Israfel, who despisest

An unimpassioned song;

To thee the laurels belong,

Best bard, because the wisest!

Merrily live, and long!

The ecstasies above 
With thy burning measures suit -

Thy grief, thy joy, thy hate, thy love,

With the fervour of thy lute -

Well may the stars be mute!

Yes, Heaven is thine; but this

Is a world of sweets and sours;

Our flowers are merely - flowers,

And the shadow of thy perfect bliss

Is the sunshine of ours.

If I could dwell

Where Israfel

Hath dwelt, and he where I,

He might not sing so wildly well

A mortal melody,

While a bolder note than this might swell

From my lyre within the sky

(HELDER, 1997, p. 13-15).

O poema "Israfel", publicado em 1831, tem o título retirado de uma passagem do Alcorão ${ }^{1}$. A referência ao anjo Israfel explicaria a presença das aspas no segundo verso. É curioso como o poema enuncia a concepção de poesia de Edgar Poe, que seria desenvolvida anos mais tarde em um ensaio publicado postumamente, em 1850, e intitulado "O princípio poético". Nesse ensaio Poe discute, entre outras coisas, a questão da finalidade meramente estética do poema, seu completo desapego às questões mundanas, sejam elas de ordem moral ou pragmática; enfim, o fato de a relação entre poesia e verdade estar necessariamente obliterada. Para Poe, o poema "é um poema e nada mais, [...] poema escrito somente por ele mesmo" (POE, 1850/1999, p. 79$)^{2}$. Após a apresentação inicial do tema do ensaio, Poe envereda

${ }^{1}$ Na edição brasileira intitulada Poemas e ensaios (1999), o poema vem acompanhado por uma epígrafe, na qual se lê: "E o anjo Israfel, em quem as fibras do coração formam um alaúde e que tem a mais doce voz de todas as criaturas de Deus” (Alcorão). Porém, em nenhuma das edições do original consultadas foi possível localizar a epígrafe, que na verdade é um verso de outro poema de Poe em que também há uma menção a Israfel: "Richer, far wilder, far diviner visions / Than even the serapher harper, Israfel, / Who has “The sweetest voice of all God's creatures [...]” (POE, 1984, p. 88).

2 "[...] but the simple fact is, that, would we but permit ourselves to look into our own souls we should immediately there discover that under the sun there neither exists nor can exist any work more thoroughly dignified - more supremely noble than this very poem - this poem per se - this poem which is a poem and nothing more - this poem written solely for the poem's sake". The Poetic principle. Cf. http://www.eapoe.org/ works/essays/poetprnb.htm. 
por uma série de argumentos que retomam de forma surpreendente as imagens elaboradas em "Israfel", quase como se o ensaio fosse um desdobramento crítico do poema. O autor identifica o senso do belo como "um instinto imortal bem profundo no espírito do homem" (id., p. $80)^{3}$, para depois afirmar que a mera reconstrução do belo na forma oral ou escrita não configura ainda a poesia. O canto aparece então como impulso em direção a algo que não pode ser atingido, uma sede que se relaciona à centelha divina vislumbrada pelo homem, mas da qual ele parece afastado: "Esta sede pertence à imortalidade do Homem. É, ao mesmo tempo, uma consequência e uma indicação de sua perene existência" (id., p. 8o) ${ }^{4}$. A questão da mortalidade e da imortalidade, tão bem expressas no poema pela antinomia entre o canto do anjo e o canto do poeta, é retrabalhada no ensaio nos seguintes termos:

E assim quando pela Poesia, ou pela Música, o mais arrebatador dos meios poéticos, nos achamos a chorar, choramos então [...], por certo impaciente e acre pesar, diante de nossa incapacidade de apreender agora, inteiramente, aqui na terra, imediatamente e para sempre, aquelas divinas e arrebatadoras alegrias, das quais, por meio do poema, ou por meio da música, percebemos apenas breves e indeterminados vislumbres (id., p. 81) 5 .

Poe parte então da diferença entre um canto divino, imagem trabalhada nas seis primeiras estrofes do poema, e um canto terreno, imagem construída na sétima estrofe, onde a terra se torna opaca quando comparada ao mundo celestial, sendo a luz do sol que banha a terra nada mais do que a sombra do êxtase do anjo. Essa comparação prepara a última estrofe, na qual o poeta imagina a troca de posições entre o seu lugar e o do anjo, fazendo o elogio de seu próprio canto terreno, e que também tem nítida relação com o ensaio. Ao discorrer, neste último, sobre a relação entre poesia e música, o autor conclui que só com a música a alma consegue criar a beleza suprema: "Pode-se dar, realmente, que aí esse sublime fim seja, de vez em quando, atingido de fato. Somos muitas vezes levados a sentir, com prazer calafriante, que de uma harpa terrena

3 "An immortal instinct, deep within the spirit of man...". The Poetic principle.

4 "This thirst belongs to the immortality of Man. It is at once a consequence and an indication of his perennial existence". The Poetic principle.

5 "And thus when by Poetry, - or when by Music, the most entrancing of the Poetic moods - we find ourselves melted into tears - we weep then [...] through excess of pleasure, but through a certain, petulant, impatient sorrow at our inability to grasp now, wholly, here on earth, at once and for ever, those divine and rapturous joys, of which through the poem, or through the music, we attain to but brief and indeterminate glimpses". The Poetic principle. 
irrompem notas que não podem deixar de ser familiares aos anjos" (id., p. 81 $)^{6}$. A ênfase na musicalidade do poema ${ }^{7}$ acentua a importância da materialidade da palavra, que pode ser observada no cuidado extremo que Poe demonstra com o ritmo - a "Criação Rítmica da Beleza" (id., p. 82) ${ }^{8}$-, as rimas internas e externas, as aliterações, o que significa buscar na própria linguagem, em sua dimensão mais concreta, aquilo que, paradoxalmente, parece estar fora dela. Afinal, para Poe, a Beleza é sempre um efeito, não uma qualidade intrínseca ao objeto, como ele próprio afirma em seu mais conhecido ensaio, "Filosofia da Composição":

\begin{abstract}
Quando, de fato, os homens falam de Beleza, querem exprimir, precisamente, não uma qualidade, como se supõe, mas um efeito [...]. Ora, designo a Beleza como a província do poema, simplesmente porque é evidente regra de arte que os efeitos deveriam jorrar de causas diretas, que os objetivos deveriam ser alcançados pelos meios melhor adaptados para atingi-los (id., 1846/1999, p. 105) 9 .
\end{abstract}

De todo modo, para Poe, sea Beleza é discernível nas formas do mundo - "o lírio [refletido] no lago, ou os olhos de Amarilis no espelho" (id., p. $80)^{10}$-, não é a repetição dessas formas que constitui a poesia. O poeta tem que apontar para aquilo que ele não pode dizer, "algo na distância que ele não foi capaz de atingir" (id., ibid. ${ }^{\mathrm{n}}$; dimensão da transcendência diante

6 "It is in Music, perhaps, that the soul most nearly attains the great end for which, when inspired by the Poetic Sentiment, it struggles - the creation of supernal Beauty. It may be, indeed, that here this sublime end is, now and then, attained in fact. We are often made to feel, with a shivering delight, that from an earthly harp are stricken notes which cannot have been unfamiliar to the angels". The Poetic principle.

${ }^{7}$ A importância conferida por Poe à musicalidade do poema pode ser observada em todos os seus ensaios, mas mais precisamente em "Análise racional do verso". Cf. POE, 1999, p. 115-163.

8 "I would define, in brief, the Poetry of words as The Rhythmical Creation of Beauty". The Poetic principle.

9 "When, indeed, men speak of Beauty, they mean, precisely, not a quality, as is supposed, but an effect [...] Now I designate Beauty as the province of the poem, merely because it is an obvious rule of Art that effects should be made to spring from direct causes - that objects should be attained through means best adapted for their attainment - no one as yet having been weak enough to deny that the peculiar elevation alluded to, is most readily attained in the poem". The Philosophy of Composition. Cf. http://www.eapoe.org/works/essays/philcomp.htm.

${ }_{10}$ "And just as the lily is repeated in the lake, or the eyes of Amaryllis in the mirror, so is the mere oral or written repetition of these forms, and sounds, and colors, and odors, and sentiments, a duplicate source of delight. But this mere repetition is not poetry". The Poetic principle.

" "There is still a something in the distance which he has been unable to attain". The Poetic principle. 
da qual só se pode calar: "And the giddy stars (so legends tell), / Ceasing their hymns, attend the spell / Of his voice, all mute."

Por último, é assinalável que, ao tentar definir seu "princípio poético", tanto no ensaio como em "Israfel", Poe o associa a "uma exaltante manifestação da alma, completamente independente daquela paixão que é a embriaguez do Coração, ou daquela verdade que é a satisfação da razão"

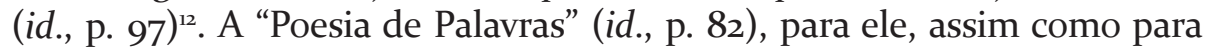
Mallarmé, nada tem a ver com uma determinada expressão sentimental - a paixão, que, segundo Poe, não eleva a alma, mas a degrada -, ou com a inteligência, a consciência, o dever e a verdade; ou seja, não é de modo algum uma operação de ordem racional, sua natureza sendo encontrada apenas no aspecto sublime - encarnado na música - que funciona como elemento capaz de indicar o caminho para apreender a beleza suprema, da qual podemos perceber apenas "breves e indeterminados vislumbres" (id., p. 81). O que Mallarmé desenvolveria em sua obra no âmbito de uma poética da "sugestão", como veremos em seguida.

\section{A TRADUÇÃO DE MALLARMÉ}

Para falar da tradução de "Israfel” por Mallarmé, é preciso primeiro destacar a importância da relação da poesia com a música para o poeta francês. Se a relação com a música sempre foi fundamental para a poesia, se a música sempre foi intrínseca à fabricação e à dicção do verso, ela ganha um estatuto diferente no século XIX e, mais especificamente, com a obra de Mallarmé, quando justamente, e talvez definitivamente, o verso, em "crise", tende a se "romper" (MALLARMÉ, 1945, p. 361)13 - ou melhor, a se "dissimular" - na prosa. "Ainda que o chamem de Prosa”, escreve o poeta, é sempre dele, do "Verso", que se trata, "se permanece alguma secreta busca de música, na reserva do Discurso” (id., p. 375) ${ }^{14}$.

${ }_{12}$ "It has been my purpose to suggest that, while this Principle itself is, strictly and simply, the Human Aspiration for Supernal Beauty, the manifestation of the Principle is always found in an elevating excitement of the Soul - quite independent of that passion which is the intoxication of the Heart - or of that Truth which is the satisfaction of the Reason". The Poetic principle.

${ }_{13}$ "Le vers, je crois, avec respect attendit que le géant qui l'identifiait à sa main tenace et plus ferme toujours de forgeron, vînt à manquer; pour, lui, se rompre" ("Crise de vers").

${ }_{14}$ "Tandis qu'il y avait, le langage régnant, d'abord à l'accorder selon son origine, pour qu'un sens auguste se produisît : en le Vers, dispensateur, ordonnateur du jeu des pages, maître du livre. Visiblement soit qu'apparaisse son intégralité, parmi les marges et du blanc; ou qu'il se dissimule, nommez-le Prose, néanmoins c'est lui si demeure quelque secrète poursuite de musique, dans la réserve du Discours". ("Quant au Livre") Em outro momento, Mallarmé define o verso livre como "en prose à coupe méditée" (“La Musique et les Lettres”, p. 654). 
A "crise de verso", nesse sentido, está longe de declarar o fim do verso. O que ela faz é problematizar sua lógica ao problematizá-lo como unidade, como lugar da identidade plena entre forma e sentido, de uma identidade acabada, estável, que seria eternizada pela forma fixa, e que prescindiria, para afirmar-se, de sua historicidade infinita. O verso em crise, ao contrário, modula a experiência não tanto do acabamento da forma quanto de seu inacabamento, de sua "inquietude": "assiste-se", escreve Mallarmé em "Crise de verso", "a uma inquietude do véu no templo com dobras significativas e um pouco seu rasgo" (id., p. 360) ${ }^{15}$.

A partir de então, a "elocução" poética deve "[descer] na noite das sonoridades" (id., p. 365) ${ }^{16}$, resistindo cada vez mais à sua acomodação à ordem figurativa, visual (às "imagens" do poema, como se costuma dizer). Como diz Maurice Blanchot (1997, p. 39), referindo-se a Mallarmé, "além de as figuras estarem encurtadas, colocadas de viés, difusas, elas se sucedem segundo um ritmo bastante rápido para que nenhuma deixe à realidade que ela circunscreve o tempo de se tornar presente para nós por seu intermédio". As palavras perdem, portanto, seu poder de remissão a uma suposta "realidade" concreta do mundo para oferecê-lo em seu "quase desparecimento vibratório", fazendo surgir o que o poeta chama de "noção pura", ou "ideia" (MALLARMÉ, 1945, p. 368) ${ }^{17}$.

Essa virtualidade volátil, fantasmática, sugestiva da linguagem verbal - "demasiado positiva" como já dizia Baudelaire (1968, p. 512), em seu artigo sobre Wagner - aparece para Mallarmé exemplarmente na música, como se evidencia nesta passagem de seu texto de 1892, em homenagem a Théodore de Banville:

Se recorro, em vista de um esclarecimento ou de generalizar, às funções da Orquestra, diante da qual permaneceu candidamente, sabiamente fechado nosso músico de palavras [trata-se de Banville], observem que os instrumentos destacam, segundo um sortilégio fácil de surpreender, o cimo, por assim ver, de naturais paisagens; evapora-as e restabelece-as, flutuantes, num estado superior [A música contrapõe-se, portanto, à positividade da percepção]. Eis

${ }_{15}$ "Qui accorde à cette fonction une place ou la première, reconnaît, là, le fait d'actualité: on assiste, comme finale d'un siècle, pas ainsi que ce fut dans le dernier, à des bouleversements; mais, hors de la place publique, à une inquiétude du voile dans le temple avec des plis significatifs et un peu sa déchirure" ("Crise de vers").

${ }_{16}$ "Pas que l'un ou l'autre élément ne s'écarte, avec avantage, vers une intégrité à part triomphant, en tant que concert muet s'il n'articule et le poème, énonciateur: de leurs communauté et retrempe, éclaire l'instrumentation jusqu'à l'évidence sous le voile, comme l'élocution descend au soir des sonorités" ("Crise de vers").

${ }_{17}$ "A quoi bon la merveille de transposer un fait de nature en sa presque disparition vibratoire selon le jeu de la parole, cependant; si ce n'est pour qu'en émane, sans la gêne d'un proche ou concret rappel, la notion pure" ("Crise de vers"). 
que para exprimir a floresta, continua Mallarmé, dissolvida no verde horizonte crepuscular, basta tal acorde desprovido quase de uma reminiscência de caça; [...]. Uma linha, alguma vibração, sumárias, e tudo se indica. Contrariamente à arte lírica, como ela foi, elocutória, em razão da necessidade, estrita, de significação. Ainda que com ele confine uma supremacia, ou rasgo de véu e lucidez, o Verbo permanece, de temas, de meios, mais maciçamente ligado à natureza [Ou seja, Mallarmé vincula a tradição da arte lírica elocutória à natureza, que ele associa ao mundo da percepção positiva] (MALLARMÉ, 1945, p. 522$)^{18}$.

Parece-me que é por meio dessa "ação negativamente criativa", a que se refere Suzanne Bernard em seu Mallarmé et la musique (1959, p.39), que o "músico de palavras", tomado pelo "tédio com respeito às coisas [que

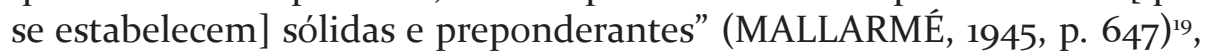
pode evocar "a noção de um objeto, escapante, que falta" (id., ibid.) ${ }^{20}$, e que cabe ao poema, "musicalmente" (id., p. 368) $)^{21}$, sugerir:

Surpreender habitualmente isso, marcá-lo, me atinge como uma obrigação de quem desencadeou o Infinito; cujo ritmo, por entre as teclas do teclado verbal, se oferece, como sob a interrogação de um dedilhado, ao emprego das palavras, aptas, quotidianas (id., p. 648) ${ }^{22}$.

${ }_{18}$ "Si je recours, en vue d'un éclaircissement ou de généraliser, aux fonctions de l'Orchestre, devant lequel resta candidement, savamment fermé notre musicien de mots, observez que les instruments détachent, selon un sortilège aisé à surprendre, la cime, pour ainsi voir, de naturels paysages; les évapore et les renoue, flottants, dans un état supérieur. Voici qu'à exprimer la forêt, fondue en le vert horizon crépusculaire, suffit tel accord dénué presque d'une réminiscence de chasse ; ou le pré, avec sa pastorale fluidité d'une après-midi écoulée, se mire et fuit dans des rappels de ruisseau. Une ligne, quelque vibration, sommaires et tout s'indique. Contrairement à l'art lyrique comme il fut, élocutoire, en raison du besoin, strict, de signification. - Quoiqu'y confine une suprématie, ou déchirement de voile et lucidité, le Verbe reste, de sujets, de moyens, plus massivement lié à la nature" "Theodore de Banville").

${ }_{19}$ "En vue qu'une attirance supérieure comme d'un vide, nous avons droit, le tirant de nous par de l'ennui à l'égard des choses si elles s'établissaient solides et prépondérantes - éperdument les détache jusqu'à s'en remplir et aussi les douer de resplendissement, à travers l'espace vacant, en des fêtes à volonté et solitaires" ("La Musique et les Lettres").

${ }_{20}$ "À l'égal de créer: la notion d'un objet, échappant qui fait défaut" ("La Musique et les Lettres").

${ }_{21}$ "Je dis: une fleur! et, hors de l'oubli où ma voix relègue aucun contour, en tant que quelque chose d'autre que les calices sus, musicalement se lève, idée même et suave, l'absente de tous bouquets" ("Crise de vers").

${ }_{22}$ "Surprendre habituellement cela, le marquer, me frappe comme une obligation de qui déchaîna l'Infini; dont le rythme, parmi les touches du clavier verbal, se rend, comme sous l'interrogation d'un doigté, à l'emploi des mots, aptes, quotidiens" ("La Musique et les Lettres"). 
A experiência poético-musical desse "isso", da "ideia" mallarmeana, talvez pudesse ser aproximada do que Jean-Luc Nancy define em seu belo livro sobre a escuta como a experiência da "ressonância", da escuta como deriva ressonante, consonante ou dissonante, pouco importa, como deriva ressonante entre o registro sensível e o registro inteligível de apreensão da matéria sonora do mundo em sua relação com o sentido. (NANCY, 2002, p. 50).

De todo modo, por meio dessas alusões a textos importantes do último Mallarmé, como Crise de verso e $A$ música e as letras, podemos perceber o quanto se tornou fundamental para ele pensar a linguagem poética em termos de sua tensão com a prosa de um lado, e com a música, de outro.

Ora, é interessante pensar que essa relação começa a se colocar desde cedo em sua obra, e para isso, com efeito, foi decisiva a descoberta de Edgar Poe e do papel fundamental que, como já vimos, ele atribuía à música. A primeira menção significativa da importância de Poe para Mallarmé está numa carta a Henri Cazalis de 1864, em que o poeta envia ao editor o poema "L'Azur", que ele espera "fiel às severas ideias que lhe foram legadas por [seu] grande mestre Edgar Poe” (MALLARMÉ, 1995, p. 161) ${ }^{23}$. Nesse poema célebre, de forte tintura baudelairiana, Mallarmé tenta conciliar a perspectiva do "efeito geral do poema" (id., p. 16o ${ }^{24}$ inspirada pelo poeta americano com a consideração do "lado estético", com a produção de um "reflexo da Beleza" (id., p. 161) ${ }^{25}$, como ele próprio diz. Ele parte "do azul [que] tortura o impotente em geral" (id., ibid.) ${ }^{26}$ para "combinar, em uma justa harmonia, o elemento dramático, hostil à ideia da Poesia pura e subjetiva, com a serenidade e a calma de linhas necessárias à Beleza” (id., p. 162$)^{27}$.

${ }_{23}$ “Toutefois, plus j’irai, plus je serai fidèle à ces sévères idées que m’a léguées mon grand maître Edgard Poe". É, aliás, também em 1864 que ele alude à experiência de traduzir Poe (p. 176). Algumas dessas traduções seriam publicadas em 1872, outras em 1876-1877. Mas a edição completa dos poemas de Poe traduzidos por Mallarmé só aparece em 1888 (1945, p. 1524).

24 "[...] le premier mot, qui revêt la première idée, outre qu'il tend par lui-même à l'effet général du poème, sert encore à préparer le dernier".

${ }_{25}$ "Reste maintenant l'autre côté à envisager, le côté esthétique. Est-ce beau, y a-t-il un reflet de la Beauté?"

26 "L'azur torture l'impuissant en général".

27 "Et ç'a été une terrible difficulté de combiner, dans une juste harmonie, l'élément dramatique, hostile à l'idée de Poésie pure et subjective, avec la sérénité et le calme de lignes nécessaires à la Beauté". 
O trabalho da dimensão musical do poema, na obra futura de Mallarmé, virá justamente fazer pender a balança para o "lado estético" em detrimento do "elemento dramático" cuja expressão ainda obseda e divide o poeta baudelairiano ${ }^{28}$ - no caso de "L'Azur", o ideal da eternidade, materializado pelo azul do céu. Tratar-se-á, cada vez mais, de aniquilar esse elemento pela amplificação da exploração musical que expulsa, abole o objeto, transformando-o em "creux néant musicien", em "oco Nada musical", para citar o poema Une dentelle s'abolit, de 1887, aqui na tradução de Augusto de Campos (MALLARMÉ, 1991, p. 72-73). Não é à toa que Mallarmé dirá dois anos mais tarde, ao mesmo Cazalis, que, "depois de ter encontrado o Nada, [encontrou] o Belo" (MALLARMÉ, 1995, p. 310) ${ }^{29}$; ou seja, o Belo ficaria desde então associado ao que talvez pudéssemos chamar de trabalho de desfiguração musical realizado pelo poema.

Como já vimos, essa associação entre a Beleza e a Música está no centro do "Israfel" de Poe. Mallarmé, de fato, não se preocupa especialmente com o aspecto formal de suas traduções, a que ele se refere como "decalques de um inimitável Poeta”, em carta de 1864 (MALLARMÉ, 1995, p. 176)30. Particularmente no caso do poema em questão (id., 1945, p. 214-215), se a tradução em prosa é elegante, ela em nada permite evocar os textos, em verso ou em prosa, de Mallarmé. Pois com frases em ordem direta e uma sintaxe bastante simples, sua tradução de modo algum recusa a ordem figurativa proposta no poema. Neste, a voz do poeta desenha a imagem de uma chama musical, "la flamme d'Israfel", canto que propicia os "célestes extases d'en haut", do "Heaven" de Poe, ainda que para supor, não sem ironia nem tampouco sem certa ambiguidade, que, se lhe fosse dada, a ele poeta que celebra o canto de Israfel, a chance de habitar aquele céu, ele talvez cantasse melhor do que Israfel; assim como Israfel talvez não cantasse tão bem quanto ele, o poeta, se estivesse aqui neste mundo de "sweets and sours", "de douceurs et d'amertumes", neste mundo repleto de "doçuras e azedumes", que constituem o inevitável "elemento dramático" de nossa existência... Mas parece-nos evidente que o que importa aqui

${ }^{28}$ Cf., por exemplo, o poema em prosa "Le Confitéor de l'artiste", em que Baudelaire dramatiza, justamente, a experiência de representação da beleza que assombra o artista. $\mathrm{O}$ poema termina assim: 'L'étude du beau est un duel où l'artiste crie de frayeur avant d'être vaincu" (Baudelaire, 1968, p. 149).

29 "En vérité, je voyage, mais dans des pays inconnus et si, pour fuir la réalité torride, je me plais à évoquer des images froides, je te dirai que je suis depuis un mois dans les plus purs glaciers de l'Esthétique - qu'après avoir trouvé le Néant, j'ai trouvé le Beau, - et que tu ne peux t'imaginer dans quelles altitudes lucides je m'aventure".

$3_{0}$ "[...] ces calques d'un inimitable Poète". Em suas "Notes sur les poèmes", publicadas ao fim do volume da Pléiade, Mallarmé, referindo-se a um outro poema, fala no "calque strict de notre version" (1945, p. 240). 
para Mallarmé é acompanhar o pensamento do poema de Poe, mais do que o próprio poema; o que vale realmente para ele é a intuição de que o poema não se faz com o "elemento dramático", com os sentimentos, com a sensibilidade que age sobre nós e nossa língua neste mundo, mas com seu silêncio, o silêncio ativo, o poema se faz com o silenciar desses sentimentos e dessa sensibilidade - e é por esse viés que a questão se radicalizaria para Mallarmé -, sobrepostos pelas "unususual strings", do instrumento, por suas "cordas extraordinárias" se traduzirmos a tradução do poeta francês. Cordas que impõem silêncio, mudez, às estrelas, "muette toutes", "all mutes", deste nosso mundo, onde as flores não passam de flores: "nos fleurs sont simplement - des fleurs", "our flowers are - merely - flowers". Silêncio imposto justamente pelo "fervor do alaúde" de Israfel, "la ferveur de [son] luth", "the fervour of [his] luth". Esse silêncio estranho - voltaremos a esse "estranho" daqui a pouco - e ressonante da música, que se faz compreender mas que talvez não se faça ouvir na tradução de Mallarmé.

A tradução de Mallarmé é, portanto, bastante prosaica em seu ritmo e sintaxe, visando talvez, acima de tudo, como se vê por esses poucos exemplos, a precisão na restituição do plano das imagens do "conteúdo" do poema. Mas nesse sentido, poderíamos especular sobre três "erros" dessa tradução pouquíssimo mallarmeana de Mallarmé.

O primeiro deles está na quinta estrofe de Poe, onde o poeta francês traduz "Therefore, thou art not wrong,/ Israfel, who despisest/ An unimpassioned song;" por "Voilà pourquoi tu n'as pas tort, Israfel, que ne satisfait pas un chant impossible". "Unimpassioned song" torna-se "chant impossible". Talvez Mallarmé quisesse ter escrito "impassible"... Mas pouco importa. Parece-nos que o que aparece aqui é o fato que o principal escolho do poeta, a partir da própria experiência de ler Poe, deixava de ser a tradução da paixão, deixava de ser, mais genericamente, a consideração de "pensamentos profundos" como um "dever" ("deep toughts are a duty"), ou a veneração da beleza encarnada pelos astros ("all the beauty which we worship in a star"), como diz Poe na estrofe anterior. O que Mallarmé passaria a "desprezar", o que a ele jamais "satisfaria", não estava do lado, como era o caso para Israfel, do "sem paixão", mas do lado do "impossível", cujas fronteiras eram determinadas pela forma fixa, de um lado, e, de outro, pela própria dimensão significante do poema, comprometida primordialmente com a figuração paradisíaca da beleza celeste. Era o "impossível" para além dessas fronteiras, acima de tudo, que se impunha ao poeta enfrentar, agora musicalmente, na "noite das sonoridades". Muitos anos mais tarde, depois de aludir, em Crise de verso, às novas práticas formais de alguns experimentadores, seus contemporâneos, do verso livre, Mallarmé observa a ampliação do campo do possível pela latência desmedida, heterodoxa, do ouvido e da língua: 
O notável é que, pela primeira vez, no curso da história literária de algum povo, em concorrência com os grandes órgãos gerais e seculares, nos quais se exalta, segundo um latente teclado, a ortodoxia, qualquer um com seu jogo e seu ouvido individuais pode compor para si um instrumento, desde que o sopre, o roce ou bata com ciência; usá-lo à parte e dedicá-lo também à Língua (id., p. 363) $)^{31}$.

Afirmar o verso pela dicção musical a contrapelo de toda métrica pré-fixada, de toda forma fixa, eis o que realizaria Mallarmé em sua "prosa" dos últimos anos e no seu Coup de Dés...

O segundo "erro" está na sétima e penúltima estrofe do poema. Ali onde Poe escreve "Our flowers are - merely - flowers, / And the shadow of thy perfect bliss/ Is the sunshine of ours", Mallarmé traduz: "Nos fleurs sont simplement - des fleurs; et l'ombre de ta félicité parfaite est le sommeil de la nôtre". (Dessa vez, teria Mallarmé querido escrever "soleil"?). Talvez porque para o poeta francês o "brilho", o "sunshine" da "felicidade perfeita", viria a estar, justamente, "à sombra" do sentido, e não em sua exposição à luz; esse brilho seria alcançado, justamente, a partir do "sono" de toda excitação altiva, do sono dos "êxtases do alto" ("the ecstasies above") e das "ardentes medidas" ("thy burning measures"), e talvez, mais do que isso, a partir do "sono" dos objetos, da dissolução de seus contornos sabidos, de sua concretude, como no caso bem conhecido da própria flor tal como dita por Mallarmé, que não pode "ser simplesmente - uma flor":

Digo: uma flor! e, para além do esquecimento a que minha voz relega todo contorno, enquanto algo diferente dos cálices sabidos, musicalmente se ergue, ideia própria e suave, a ausente de todos os buquês (id., p. 368) ${ }^{32}$.

Assim, o que se "ergue" "musicalmente" à escuta para Mallarmé, a "ideia própria e suave" da "ausente de todos os buquês", não passa - e aqui evocamos novamente $A$ Escuta de Jean-Luc Nancy - da "remissão de uma presença a outra coisa que não ela mesma, ou a uma ausência de coisa, a remissão de um aqui a um alhures, de um dado a um dom, e sempre, de algum modo, de alguma coisa a nada", e, continua Nancy, "isso se chama [...] sentido" (NANCY, 2002, p. 50).

31 "Le remarquable est que, pour la première fois, au cours de l'histoire littéraire d'aucun peuple, concurremment aux grandes orgues générales et séculaires, où s'exalte, d'après un latent clavier, l'orthodoxie, quiconque avec son jeu et son ouïe individuels se peut composer un instrument, dès qu'il souffle, le frôle ou frappe avec science; en user à part et le dédier aussi à la Langue" ("Crise de vers").

${ }^{32} \mathrm{Cf}$. nota 12. 
É por esse viés que queremos compreender o terceiro "erro" de tradução de Mallarmé, e que tem a ver com essa ressonância irredutível entre os registros sensível e inteligível que, para Nancy, caracteriza toda escuta em sua abertura ao sentido. Repetido na primeira e na última estrofe do poema, o "wildly well" que adverbializa o canto de Israfel no poema de Poe se torna em tradução "étrangement bien". Soar "estranhamente bem". Entre uma língua e outra, entre o verbal e o musical, entre o som e o sentido, entre o sensível e o inteligível, entre o estranho e o familiar... Não seria esse o maior elogio que poderíamos fazer a uma tradução?

\section{A PRÁTICA TRADUTÓRIA DE ARTAUD}

Se nas poéticas de Poe e Mallarmé a música desempenhava um papel crucial, para Artaud a questão da musicalidade da poesia será trabalhada segundo um "princípio poético" bastante diferente. Artaud também se mostra atento à materialidade da linguagem, mas já não é para alcançar qualquer tipo de melodia a funcionar como ponte que se ergue do poema em direção à beleza, mas sim para elaborar uma poética da intensidade, encenando uma espécie de performance corporal que não é estranha às suas propostas para o teatro. Aquilo que para Poe remetia à dimensão sublime da arte e instaurava uma separação entre o mundo divino e o mundo terreno, e que em Mallarmé evocava o "Nada" a partir do qual se chega ao "Belo", para Artaud se transformará na busca pelo ritmo, pela vibração poética. Se ainda se pode falar de musicalidade, certamente não é mais de harmonia ou de beleza que se trata, mas de potência rítmica, pulsação que se inscreve na instância do corpo, tal como se lê em "O teatro da Crueldade (primeiro manifesto)":

Essa linguagem objetiva e concreta do teatro serve para cercar, encerrar órgãos. [...] Ela impele a voz. Utiliza vibrações e qualidades de voz. Faz ritmos golpearem loucamente. Martela sons. Visa exaltar, exacerbar, encantar, deter a sensibilidade (ARTAUD, 1964, p. 138)33.

33 “[C]e langage objectif et concret du théâtre sert à coincer, à enserrer des organes. Il court dans la sensibilité. [...] Il pousse la voix. Il utilise des vibrations et des qualités de voix. Il fait piétiner éperdument des rythmes. Il pilonne des sons. Il vise à exalter, à engourdir, à charmer, à arrêter la sensibilité" ("Le théâtre de la cruauté - Premier Manifeste"). 
A própria separação entre corpo e espírito, entre terra e céu, reiterada pelo poema de Poe, deixa de fazer sentido ${ }^{34}$, pois o que está em jogo é justamente a recusa de toda espécie de dicotomia. É certo que há em Artaud um rebaixamento do espírito - aparente em sua tradução do poema de Poe -, mas o espírito é rebaixado por se estabelecer como dimensão oposta e superior ao corpo. Vale lembrar que Poe, no final do ensaio "O princípio poético", faz o elogio de Alfred Tennyson, dizendo que ele é o mais nobre dos poetas porque a emoção poética causada por ele "é todas as vezes a mais etérea", e conclui: "Nenhum poeta é tão pouco da terra, material" (POE, 1999, p. 96).

Se, para Poe, o poema aponta para esse lugar da transcendência, para Artaud o que há é uma espécie de imanência, e qualquer discussão em torno da beleza e de seu caráter inefável é pouco ou nada produtiva; a valorização do aspecto concreto da linguagem é inseparável de certa inscrição da poesia na dimensão da própria vida - o que, como veremos, fica evidente na tradução de "Israfel" -, pois o que está em questão é a discussão "no interior de um pensamento erodido e de uma linguagem fraturada, que incidirá na busca para se tomar ou se refazer um corpo" (KIFFER, 2003, p. 25).

É importante observar que o poeta, segundo Jean-Michel Rey (2002), começou a traduzir no período em que ficou internado no asilo de Rodez, incentivado por seu médico. O problema enfrentado por Artaud era o de como escrever numa língua tão codificada como a francesa, afrouxando a dimensão cerceadora da linguagem, abrindo brechas que lhe permitissem remoldá-la e reconstruir seu pensamento. $\mathrm{O}$ contato com a obra dos autores delíngua inglesa-em especial Lewis Carroll eEdgar Poe-foi decisivo:através de uma prática de leitura, escrita e tradução, Artaud dedicou-se novamente à produção de sua obra, ele que se identificava a outros "supliciados da linguagem" (ARTAUD, 1979, IX, p. 170)35, e que no "Preâmbulo" - texto que escreve em 1946 quando Gaston Gallimard lhe propõe a publicação de suas obras - afirma que "quando quis escrever [perdeu suas] palavras" (ARTAUD, 1976, I, p. 9) ${ }^{36}$. Para construir sua própria língua dentro da língua francesa, Artaud terá então que passar por outras línguas e por outras poéticas por meio da revisita a poemas já escritos numa língua estrangeira. Entretanto, seu gesto tradutório apontará para uma atividade usurpadora, pois Artaud não se submete ao original, mas cria a partir dele.

34 Cito aqui o trabalho de Ana Kiffer, Antonin Artaud: uma poética do pensamento, no qual a autora comenta a poética de Artaud à luz desse movimento de superação das dualidades.

35 "J'aime les poèmes des affamés, des malades, des parias, des empoisonnés: François Villon, Charles Baudelaire, Edgar Poe, Gérard de Nerval, et les poèmes des suppliciés du langage qui sont en perte dans leurs écrits [...]".

${ }_{36}$ "[...] Je sais que quand j'ai voulu écrire j'ai raté mes mots et c'est tout" ("Préambule"). 
O gesto usurpatório, segundo Jean-Michel Rey, já havia ocorrido anteriormente com o capítulo do Humpty Dumpty em Through de looking glass, de Lewis Carroll. Ao traduzi-lo, Artaud introduz inúmeras modificações no texto, sobretudo no poema sobre os peixes que encerra o capítulo. Não menos interessante é o comentário que ele apresenta no posfácio:

Eu senti que esse pequeno poema [de Lewis Carroll] fui eu que o pensei e escrevi, em outros séculos, e que reencontrei minha própria obra, entre as mãos de Lewis Carroll. [...] Aliás, pode-se comparar esse pequeno poema ao de Lewis Carroll no texto em inglês e será evidente que ele me pertence realmente e não é de forma alguma a versão francesa de um texto inglês (ARTAUD, 1979, IX, 147) $)^{37}$.

Há aqui um movimento de "plagiotropia", como diria Haroldo de Campos (CAMPOS, 1992, p. 84). O poeta se apropria do texto anterior, produzindo a partir dele uma obra que se torna própria, em que ele pode grafar a sua assinatura. Ao traduzir Poe, Artaud encontra uma dicção própria, que não se separa de sua necessidade de sobrevivência, de produzir brechas e espaços de respiração, e ao repetir o gesto de tradução efetuado por Mallarmé, outro poeta de língua francesa, inscreve-se também numa espécie de genealogia, o que é importante para que se torne um autor.

A comparação com a tradução de "Israfel" por Mallarmé permite algumas considerações para a definição da poética de Artaud: o poema tem início com a apresentação do anjo Israfel, cujo canto é descrito por Poe por meio do advérbio "wildly". Lembremos que Mallarmé havia traduzido essa passagem como "nul ne chante si étrangement bien que l'ange Israfel"; o anjo que no poema de Poe canta "wildly well", isto é, de forma extraordinária, extraordinariamente bem, terá, na tradução de Mallarmé, o seu canto associado a um caráter de estranha familiaridade, como referimos em nosso comentário.

Essa modificação introduzida por Mallarmé foi, muito provavelmente, sentida por Artaud, pois apesar de fazer uma modificação significativa em que o advérbio "wildly" dá lugar ao adjetivo "sauvage" - "pas de chant plus sauvage au fond de l'absolu" -, Artaud recupera o "étrange" alguns versos mais adiante: "et chaque pulsation de cet oracle étrange". E é justamente a

37 "J'ai eu le sentiment [...] que ce petit poème [de Lewis Carroll] c'est moi qui l'avait et pensé et écrit, en d'autres siècles, et que je retrouvais ma propre œuvre entre les mains de Lewis Carroll. D'ailleurs ce petit poème [Artaud parle ici de sa traduction], on pourra le comparer avec celui de Lewis Carroll dans le texte anglais, et on se rendra compte qu'il m'appartient en propre et n'est pas du tout la version française d'un texte anglais" ("Postscriptum au texte L'Arve et l'Aume"). 
partir desse verso que podemos notar o gesto transgressor e usurpador de Artaud em relação ao poema original. Se compararmos a primeira estrofe em todas as versões, veremos quea de Mallarmé, apesar de ter transformado o poema numa versão em prosa, preserva muito da estrutura do original, inclusive o pequeno aparte entre parêntesis. A versão de Artaud, por sua vez, introduzirá uma série de imagens e temas que não fazem parte do poema original, assim como fizera com Lewis Carroll no episódio há pouco mencionado. A estrofe, que no poema de Poe apresentava sete versos, passa agora a ter treze, sendo que o sexto, o sétimo e o oitavo versos não encontram qualquer correspondente no poema de Poe.

O primeiro verso apresenta uma modificação assinalável: no poema de Poe há "um espírito que vive no céu [...] e cujas fibras do coração são um alaúde"; Artaud, ao fazer a sua versão, descreve um coração que vive no céu - "Au ciel il est un coeur dont les cordes sont l'âme d'un luth / comme un esprit de flamme, là où l'âme ne monte plus", fazendo com que o "espírito" passe a ser apenas um termo de comparação, uma metáfora. Há, nesse caso, uma mudança de ênfase na relação proposta por Poe entre a poesia e sua dimensão propriamente religiosa, sublime, já que o anjo não é mais representado por Artaud como um "espírito", mas como um órgão do corpo humano. Note-se, além disso, a introdução da palavra "âme", não para reforçar o seu significado habitual, mas para ultrapassá-lo, sendo quase uma provocação. Há uma passagem do significado abstrato ao concreto, pois a palavra "alma" apresenta uma bissemia presente tanto na língua francesa como na portuguesa: além de remeter a "espírito", referese também a um pequeno cilindro de madeira colocado entre o tampo e o fundo dos instrumentos de corda. Nessa segunda acepção, a palavra está totalmente afastada do seu significado transcendente para adquirir uma tonalidade mais material. Tudo indica que há de fato uma espécie de provocação, já que volta a aparecer no final do segundo verso, aqui para remeter ao lugar ocupado pelo coração, que seria inacessível à alma.

No sexto verso o anjo Israfel é comparado a um "oracle étrange", no sétimo surge o "Monte Sinai", e no penúltimo verso Artaud insere a palavra "dictame", a respeito da qual Jean-Michel Rey constrói uma longa interpretação, considerando-a inclusive a chave para a construção da poética de Artaud, sendo o dictame a imagem utilizada pelo escritor para fundar a sua própria $v_{0 z}{ }^{38}$. Todo o final da primeira estrofe é exemplar para a poética de Artaud: "Les astres enivrés [...] / assistent ébahis /

${ }^{8}$ Jean-Michel Rey (2002) faz um longo percurso no qual demonstra o lugar dessa palavra na tradição literária ocidental, passando por Aristóteles, Virgílio, Tasso, Baudelaire, Michelet, Gérard de Nerval etc., e demonstrando a relação entre o princípio curativo associado a essa planta (bálsamo) e o dictare latino, o que inclui a ideia de receber uma palavra que vem do exterior. 
aux magiques scansions du dictame inouï / que le Barde d'en Haut épèle avec Sa Vie." Artaud introduz aqui a ideia de escansão, uma complicada modificação do original de Poe (the spell of his voice) e que Mallarmé havia traduzido como "le charme de sa voix". A escansão é a decomposição do verso que será efetuada por uma performance oral, o soletrar, e Artaud relaciona tal operação à dimensão da própria vida, que não à toa aparece com letra maiúscula. É com a vida que o bardo soletra, é com a vida que a poesia se deixa escrever: "Se sou poeta ou ator não é para escrever ou declamar poesias, mas para vivê-las" (ARTAUD, 1979, p. 154) ${ }^{39}$.

O poema de Poe, desde o título, apresenta uma relação com a religiosidade: Israfel é um anjo mencionado no Alcorão, e a primeira estrofe do poema de Poe contém um verso retirado justamente desse livro sagrado. Na versão de Artaud há a opção por um apagamento da relação entre poesia e transcendência, presente no poema de Poe, conferindo ao corpo - que não se separa da dimensão da vida - um lugar privilegiado. Basta observar que ainda na primeira estrofe Artaud introduz a ideia muito corporal da pulsação ("chaque pulsation de cet oracle étrange"), que vai contaminando o restante do poema. Na segunda estrofe, por exemplo, Artaud transforma a dinâmica do encantamento num processo de êxtase corporal, no qual o vacilar da lua e o seu "enamoramento" ("tottering above / [...] the enamoured moon") dão lugar a um "transe mágico": "la lune soulevée d’un transport extatique / s'embrase énamourée, et la transe magique [...]”. Na terceira estrofe Artaud retoma a ideia de uma "pulsação estranha" ("pulsation étrange"), sendo que a musicalidade tão almejada por Poe cede o seu lugar a um ritmo puramente corporal - as batidas cardíacas ("luth cardiaque de Dieu") da terceira estrofe -, e logo a seguir eclode na imagem de um "espasmo": "tremblement de l'Âme propre au spasme”. Na sexta estrofe o ritmo cardíaco é retomado nos "battements de sang" ("pulsações de sangue"). É impressionante como a atuação vocal do anjo de Artaud se aproxima da performance por ele visada e relacionada ao espetáculo:

Todo espetáculo conterá um elemento físico e objetivo, sensível a todos. Gritos, lamentações, aparições, surpresas, [...] beleza encantatória das vozes, magia da harmonia, raras notas musicais, cores dos objetos, ritmo físico dos movimentos cujo crescendo e decrescendo acompanharão a pulsação de movimentos familiares a todos [...] (ARTAUD, 1964, p. 141-142) ${ }^{40}$.

39 "Si je suis poète ou acteur ce n'est pas pour écrire ou déclamer des poésies, mais pour les vivre" ("Lettres de Rodez").

$4^{4}$ "Tout spectacle contiendra un élément physique et objectif, sensible à tous. Cris, plaints, apparitions, surprises, [...] beauté incantatoire des voix, charme de l'harmonie, notes rares de la musique, couleurs des objets, rythme physique des mouvements dont le crescendo et le decrescendo épousera la pulsation de mouvements familiers à tous [...]" ("Le Théâtre de la cruauté"). 
Artaud inventa frases inteiras que também não têm nenhuma relação com o original, procurando reescrever o poema ao acentuar a distância entre a sua poética e a de Poe. Nas duas últimas estrofes a importância da dimensão sublime do canto se perde, o que se estende à proposta final do poema: a inversão entre o lugar do poeta e o do anjo. No poema de Poe, supõe-se que com a troca de lugares o anjo, por estar na terra, não cantaria tão bem uma melodia mortal ("he might not sing so wildly well a mortal melody"), enquanto o poeta da terra, por estar num lugar privilegiado, cantaria com exuberância. Afinal, parece que o que está em jogo para Poe é pensar o limite do canto terreno, no mesmo gesto em que avalia a genialidade do poeta. Artaud, por sua vez, traduzirá essa passagem enfatizando a irredutibilidade do canto terreno e mortal do poeta a qualquer condição, mesmo que celeste ("bien qu'à sa place je chanterai alors une mélodie mortelle"). Resta pensar que se, para Poe, o que estava em questão no poema era a possibilidade/impossibilidade do canto terreno, ou seja, o talento do poeta, para Artaud o ponto crucial não está relacionado aos atributos do poeta, e sim às condições do poetar. A poesia só é possível porque ela tem uma dimensão material, porque é um canto terreno e mortal.

Tal deslocamento é visível na estrofe anterior, a que antecede a conclusão do poema. Note-se que a tradução de Artaud desembocará na inversão entre o céu e a terra: "Oui, le monde du Ciel, ô Israfel, est tien / mais sa terre ne sait que le sûr ou le sage, / [...] pour elle, il n'y a pas de rêve ni d'image / à ajouter à ce qui est certain. / Les fleurs sont vérités comme fleurs, ô mirage, / et l'ombre d'un pleur seul tombé de ton visage / brille comme soleil sur ce monde sans cour" (HELDER, 1997, p.20). A terra à qual Artaud se refere não é mais o mundo terreno, aquele em que o poeta canta, mas outra terra, uma terra situada no Céu (sa terre), uma terra sem coração, terra de certezas, onde as flores são sempre flores - notese a ironia, a terra de certezas como pura miragem! Em Poe o que estava em questão era outro problema (our flowers are merely - flowers), o do esvaziamento do mundo do poeta em relação ao mundo celeste, vendo nele uma espécie de simulacro do mundo verdadeiro. Artaud, ao incluir outra terra no mundo do anjo, opera por uma lógica da contaminação, e agora é essa terra celeste que é opaca - porque determinada, precisa, inalterável, terra da verdade -, e não a terra em que o poeta canta. $\mathrm{O}$ mundo da certeza e da univocidade certamente não é, nem poderia ser, a terra da poesia. 


\section{HERBERTO HELDER E A TRADUÇÃO DE ARTAUD}

Se o tema básico com que este trabalho dialoga remete a um anjo, Israfel, não podemos deixar de citar aqui outro anjo cuja presença se dá transversalmente: Lúcifer, anjo que Haroldo de Campos elege, contra Benjamin, e ao mesmo tempo retomando-o, para reivindicar a tradução da tradução como gesto usurpatório. Para Haroldo, se Benjamin em "A tarefa do tradutor" conseguiu, por um lado, desfazer-se dos ideais de transparência e fidelidade que sempre assombraram a tradução, se "promoveu o aspecto estranhante da operação tradutora como 'transpoetização' da forma de uma outra forma" (CAMPOS, 1981, p. 81), por outro lado ele mantém ainda um último dogma, o da retradução de traduções de poesia. Para Haroldo de Campos, é necessário "transformar a 'missão angélica' do tradutor de poesia numa 'empresa luciferina”' (id., p. 84), tarefa que Artaud e Herberto Helder executaram cada um à sua maneira.

Na sequência das traduções de "Israfel" em Doze nós numa corda, Herberto Helder apresenta a sua tradução a partir da versão de Artaud, e não do original de $\mathrm{Poe}^{41}$. Tal gesto aponta mais uma vez para o estabelecimento de uma rede de afinidades, pois Artaud é certamente uma referência importantíssima para a poética herbertiana ${ }^{42}$. Para ambos, a escrita é uma operação de abertura dos sentidos que não estaria mais identificada a uma servidão anatômica, ou a uma hierarquização dos órgãos. São poéticas estruturadas segundo um regime de fragmentações que se estendem do corpo à linguagem. Em Helder tornam-se recorrentes as imagens fragmentárias: cabeça, dedos, mãos, boca, vagina, ânus. $\mathrm{O}$ lugar central do coração, que Artaud instaurará no poema de Poe por

${ }^{41}$ Há também uma série de nove poemas de Artaud traduzidos no livro, retirados das seguintes obras que estão reunidas no primeiro volume de suas Euvres Complètes: Correspondance avec Jacques Rivière, L'ombilic des limbes, Premiers poèmes (1913-1923) e Poèmes (1924-1935).

${ }^{42}$ Outra referência a Artaud comparece num texto de Photomaton $\mathcal{E}$ Vox intitulado "os quartos incendiados", no qual Herberto Helder se refere à loucura de Artaud e a seu calvário nos asilos psiquiátricos: "Quem é que entretanto chega de Marselha passando pelo juvenil manicómio dos outros, na escrutação do profeta? Artaud, aquele a quem fugia a cabeça" (HELDER, 1995, p. 66). Há ainda uma terceira menção ao poeta francês, dessa vez com o objetivo de atacar o aspecto "doutrinário" da postura de Breton em relação ao Surrealismo: "Bem, prestou alguns serviços involuntários. Artaud apoiouse na disciplina do regimento para desertar num salto louco; algumas referências surrealistas foram úteis, à distância, para Michaux. Tudo enriquece a originalidade dos espíritos originais. Artaud e Michaux agarraram em duas ou três colheradas da mixórdia e foram com elas, prepararam o seu festim mirífico: não há nada nas iguarias deles que saiba a rancho" (HELDER, 2001, p. 194). 
oposição ao espírito, deve ter lhe chamado a atenção, fazendo com que mantivesse todos os acréscimos de ordem corporal. Para Helder é a partir do corpo que o poema se produz, evocando em sua poética, de forma próxima a Artaud, a energia e os estados de êxtase, tal como se pode ler no texto "galinholas", de Photomaton $\mathcal{E}$ Vox:

(O verbo impregnava a terra, a energia impregnava a terra).

Tudo isto é para a grande máquina circulatória, o aparelho digestivo, o sistema respiratório. Coisas do corpo que precisa de transe, êxtase. Essa é a significação. Estamos a trabalhar com instrumentos que abalam tudo. Há uma energia geral comutada à passagem pelo corpo (HELDER, 1995, p. 123).

Mesmo assim, algumas diferenças são assinaláveis, e de certo modo o poema se torna menos radical na tradução de Helder: na primeira estrofe, a ironia introduzida por Artaud no primeiro verso em torno da palavra "alma" desaparece, ainda que o lugar central ocupado pelo coração permaneça bem demarcado43: "No céu vive um coração de que as fibras são as cordas de um alaúde / como a alma de uma labareda, no céu mais alto" (HELDER, 1997, p. 21), assim como ele também não recupera o descompasso entre a ordem do corpo, condensada no coração, e a alma ("Au ciel il est un cour dont les cordes sont l'âme d'un luth / comme un esprit de flamme, là où l'âme ne monte plus"), estando a alma impossibilitada de atingir o lugar mais alto do coração. Na tradução de Helder essa última menção ao rebaixamento da alma em relação ao coração simplesmente desaparece.

Também as imagens da escansão e do "dictame" "magiques scansions du dictame inoui"), que em Artaud remetiam à importância da performance oral, são traduzidas por Helder como "inaudita ascensão daquela música inaudita”, o que é bastante curioso, até mesmo pela semelhança entre as palavras escansão (scansion) e ascensão (ascension), podendo sugerir uma distração por parte do tradutor; por último, há também uma pequena, porém significativa, alteração: o bardo de Artaud soletrava o dictame com sua vida ("[... magiques scansions du dictame inouï/ que le Barde d'en Haut épèle avec Sa Vie”), já para Helder (1995, p. 21): "o mágico Bardo do alto soletra enquanto soletra a sua vida, cantando”. A modificação permite-nos entender as aproximações e afastamentos entre as poéticas dos dois autores. Para Artaud a escrita não se separa de uma estratégia de sobrevivência, escrever com o corpo para reescrever o corpo, para torná-lo possível. Para Helder a escrita é também da ordem da vitalidade - "A escrita nasce diretamente do corpo, do seu movimento" (HELDER, 1995, p. 136) -, mas é

${ }^{43}$ Lembremos que Herberto Helder também trabalha com uma poética que é essencialmente corporal. 
sobretudo um processo de potencialização da própria língua, não estando em questão a ideia de estar privado da palavra, ou de a escavação da palavra ser literalmente um ato de sobrevivência, como foi o caso para Artaud.

Helder mantém ainda o grande deslocamento efetuado por Artaud nas duas últimas estrofes do poema, mas ao revisitar a tradução do poeta francês talvez ele não tenha sido sensível à inclusão do pronome possesivo (sa terre) que irá duplicar a imagem da terra, dando origem a uma terra celestial e a uma terra terrena. Na tradução de Artaud, como vimos, a inversão final entre o canto do anjo e o canto do poeta se dá pela suposição de que a terra na qual o anjo canta é uma terra de certezas, por isso infrutífera para a poesia. Na tradução de Helder essa imagem acaba ficando um pouco confusa: na terra (e aqui se trata apenas da terra terrena) "as flores são verdadeiras como flores", o que já é problemático quando lembramos que em seguida essa "verdade" é evocada enquanto miragem (ó miragem).

De todo modo, a versão de Helder recupera o sentido final da tradução de Artaud, justamente quando na última estrofe é o poeta da terra que se imagina entoando um canto mortal no lugar do anjo: "ainda que em seu lugar eu entoasse um canto mortal”. Resta perceber que para Helder, assim como para Artaud, o que está em questão é a possibilidade de invenção de uma linguagem performativa e da intensidade - "Todo o discurso é apenas o símbolo de uma inflexão/ da voz/ a insinuação de um gesto uma temperatura [...]" (HELDER, 2004, p. 273) - linguagem em que a poesia se torna o próprio gesto de cantar.

\section{REFERÊNCIAS BIBLIOGRÁFICAS}

ARTAUD, Antonin. Le théâtre et son double. Paris: Gallimard, 1964.

ARTAUD, Antonin. Le pèse-nerf. In: Euvres complètes I. Paris: Gallimard, 1976.

ARTAUD, Antonin. Préambule. In: CEuvres complètes I. Paris: Gallimard, 1976.

ARTAUD, Antonin. Les Tarahumaras. In: Euvres complètes IX: Paris: Gallimard, 1979.

BAUDELAIRE, Charles. Euvres complètes. Marcel A. Ruff (org.) Paris: Seuil, 1968.

BENJAMIN, Walter. A tarefa do tradutor. Trad. de Susana Kampff Lages. In: Escritos sobre mito e linguagem. São Paulo: Editora 34/Duas cidades, 2011. p. 101-119.

BERNARD, Suzanne. Mallarmé et la musique. Paris: Librairie Nizet, 1959.

BLANCHOT, Maurice. A parte do fogo. Trad. de Ana Maria Scherer. Rio de Janeiro: Rocco, 1997 . 
198 - Remate de Males 35.1

CAMPOS, Haroldo de. Post-Scriptum; Transluciferação Mefistofaústica. In: Deus e o Diabo no Fausto de Goethe. São Paulo: Perspectiva, 1981. p. 179-191.

CAMPOS, Haroldo de. O que é mais importante: a escrita ou o escrito? Revista USP. São Paulo, n. 15, p. 77-84, set./out./nov. 1992.

HELDER, Herberto. Doze nós numa corda. Lisboa: Assírio \& Alvim, 1997.

HELDER, Herberto. Ou o poema contínuo. Lisboa: Assírio \& Alvim, 2004.

HELDER, Herberto. Photomaton E Vox. Lisboa Assírio \& Alvim, 1995.

HELDER, Herberto. Entrevista. In: Inimigo Rumor, n.11. Rio de Janeiro: 7 letras, $2^{\circ}$ semestre de 2001.

KIFFER, Ana. Antonin Artaud - uma poética do pensamento. La Coruña: BibliotecaArquivo Teatral Francisco Pillado Mayor, 2003.

MALLARMÉ, Stéphane. Euvres complètes. Henri Mondor e G. Jean-Aubry (org.). Paris: Gallimard, 1945. (Bibliothèque de la Pléiade).

MALLARMÉ, Stéphane. Mallarmé. Augusto de Campos, Décio Pignatari e Haroldo de Campos (org. e trad.). São Paulo: Editora Perspectiva, 1991.

MALLARMÉ, Stéphane. Correspondance. Lettres sur la poésie. Bertrand Marchal (org.). Paris: Gallimard, 1995.

NANCY, Jean-Luc. L'Écoute. Paris: Galilée, 2002.

POE, Edgar Allan. Poetry and tales. New York: Library of America, 1984.

MALLARMÉ, Stéphane. Poemas e ensaios. Trad. de Oscar Mendes e Milton Amado. São Paulo: Globo, 1999.

REY, Jean Michel. O nascimento da poesia: Antonin Artaud. Trad. de Ruth Silviano Brandão. Belo Horizonte: Autêntica, 2002. 